\title{
Respostas de Genótipos de Coffea spp. a Diferentes Populações de Meloidogyne exigua
}

\author{
Rodrigo V. Silva ${ }^{1}$, Rosângela D.L. Oliveira ${ }^{1}$, Antonio A. Pereira ${ }^{2}$ \& Dalila J. Sêni ${ }^{1}$ \\ ${ }^{1}$ Departamento de Fitopatologia, Universidade Federal de Viçosa, e-mail: rvsilva@vicosa.ufv.br; ${ }^{2}$ EPAMIG-CTZM, \\ CEP 36570-000, Viçosa, MG, Brasil
}

Autor para correspondência: Rodrigo V. Silva

SILVA, R.V., OLIVEIRA, R.D.L., PEREIRA, A.A. \& SÊNI, D.J. Respostas de genótipos de Coffea spp. a diferentes populações de Meloidogyne exigua. Fitopatologia Brasileira 32:205-212. 2007.

\section{RESUMO}

Em Meloidogyne exigua, um dos principais patógenos do cafeeiro no Brasil, já foram observadas variabilidade bioquímica, molecular, morfológica e fisiológica. No entanto, a expressão desta variabilidade quanto à virulência a genótipos de cafeeiro não é bem conhecida. O objetivo deste trabalho foi estudar o efeito de populações de $M$. exigua, as quais exibiam diferentes fenótipos de esterase e preferências por hospedeiros, em 25 genótipos de cafeeiro, com o propósito de se conhecer melhor a interação de biótipos desse nematóide com o gênero Coffea. Seis mudas de cafeeiro por tratamento foram inoculadas no estádio de 3 a 4 pares de folhas definitivas com 5.000 ovos de cada população de M. exigua por planta. O número de galhas e ovos por sistema radicular e a biomassa da matéria fresca das raízes foram avaliados aos 110 dias após a inoculação. Em função da reação frente às populações de M. exigua, os genótipos de Coffea spp. foram classificados em 14 suscetíveis, 5 imunes e 6 segregantes. Estes últimos segregaram de maneira diferenciada conforme a população do patógeno, evidenciando a existência de variabilidade intraespecífica em relação à virulência ao cafeeiro. Assim, o uso de diferentes populações desse patógeno, que englobem essa variabilidade é fundamental no desenvolvimento de cultivares resistentes.

Palavras-chave adicionais: Nematóides das galhas, resistência, variabilidade, cafeeiro.

\begin{abstract}
Responses of different genotypes of Coffea spp. to Meloidogyne exigua populations

In Brazil, Meloidogyne exigua is one of the most important pathogens that attack coffee plants. Morphological, biochemical, molecular and physiological variabilities have been observed in $M$. exigua, but the expression of these variabilities in coffee genotypes is not well known. To evaluate the effect of M. exigua on 25 Coffea spp. genotypes, populations exhibiting distinct esterase phenotypes and host suitability variations were selected. Thus, coffee seedlings at the stage of 3-4 sets of two leaves were inoculated with 5000 eggs of either population, with each treatment including six replicates. The evaluation occurred 110 days after inoculation, by counting galls and eggs per root system and measuring root fresh weight. According to the genotypes' reaction, three groups of Coffea spp. were detected: fourteen expressed susceptible reaction, six segregated and five were immune to $M$. exigua populations. The segregating genotypes behaved in a different way in relation to the four populations. Thus, the utilization of different populations showing this variability is fundamental for a breeding program that aims to develop resistant cultivars.
\end{abstract}

Additional keywords: Root-knot nematode, resistance, variability, coffee.

\section{INTRODUÇÃO}

O café é um dos mais importantes produtos agrícolas comercializados no mundo e o Brasil é o seu maior produtor e exportador (Conab, 2006). Dentre as mais de 80 espécies no gênero Coffea (Cros, 1994), somente C. arabica L. e C. canephora (Gonçalves \& Silvarolla, 2001) são cultivadas comercialmente. A primeira representa mais de $70 \%$ do café comercializado no mundo, entretanto, outras espécies são importantes no melhoramento de $C$. arabica, por possuírem genes de resistência a pragas e doenças e a condições adversas do ambiente (Gonçalves \& Silvarolla, 2001).

Parte da Dissertação de Mestrado em Fitopatologia do primeiro autor. Universidade Federal de Viçosa. Viçosa MG. 2005.
Em países como o Brasil, Colômbia, Venezuela e em alguns da América Central, Meloidogyne exigua Goeldi, 1887, representa um sério problema para a cafeicultura, pois constitui um fator limitante para a obtenção de alta produtividade em cafeeiros do tipo arábica (Campos \& Villain, 2005; Barbosa et al., 2004). Esta espécie pode causar perdas na produtividade da ordem de $45 \%$ em cafezais do noroeste do Estado do Rio de Janeiro (Barbosa et al., 2004).

A utilização de cultivares de cafeeiros resistentes apresenta-se como a forma mais econômica para substituir lavouras improdutivas e infectadas por Meloidogyne spp. $\mathrm{O}$ desenvolvimento de cultivares com resistência a este nematóide é possível devido à diversidade genética existente no gênero Coffea, a qual se encontra disponível nos centros de pesquisa brasileiros. Entretanto, o sucesso desta prática 
vai depender do conhecimento das espécies, raças ou biótipos do nematóide, presentes na área, pois a resistência é na maioria das vezes específica (Roberts et al., 1998).

Variabilidade genética é conhecida em M. exigua. Esta espécie se reproduz por partenogênese meiótica facultativa, um modo de reprodução com menor estabilidade genética quando comparado a outras espécies que se reproduzem por partenogênese mitótica (Esbenshade \& Triantaphyllou, 1985). Variações em populações de Meloidogyne spp. em cafeeiros foram observadas por Oliveira et al. (2005b) ao estudar populações provenientes de cafeeiros da Zona da Mata de Minas Gerais. As fêmeas de algumas populações oriundas do município de São João do Manhuaçu apresentavam configurações perineais semelhantes às de $M$. arenaria, mas na análise isoenzimática, todas apresentaram o fenótipo de esterase típico de M. exigua.

Estudos envolvendo técnicas moleculares também têm demonstrado a existência de variabilidade dentro da espécie M. exigua. Randig et al. (2002), por meio da técnica de RAPD (DNA polimórfico amplificado ao acaso), detectaram alto nível de polimorfismo intraespecífico $(67,5 \%)$ entre as populações de $M$. exigua provenientes de cafeeiros e de seringueira. Curiosamente, tais populações oriundas de cafeeiro e seringueira têm revelado diferenças bioquímicas quanto à enzima esterase, o que culminou com a detecção de quatro fenótipos, E1, E1a, E1b e E2 (Esbenshade \& Triantaphyllou, 1985; Carneiro \& Almeida, 2000; Oliveira et al., 2005b). Mas, variabilidade fisiológica também tem sido encontrada, como no trabalho de Carneiro \& Almeida (2000), que propuseram a separação das "raças fisiológicas" com base na capacidade de reprodução em plantas de diferentes espécies botânicas.

É indiscutível esta variabilidade em genótipos de cafeeiro, mas a expressão da mesma não é bem conhecida. Híbridos de C. arabica e C. canephora, como por exemplo, $\mathrm{H}$ 4782-7-585, H 4782-7-785, H 4782-7-925, que são resistentes à ferrugem do cafeeiro (Hemileia vastatrix Berk. et Br., apresentaram também resistência a $M$. exigua (Gonçalves \& Pereira, 1998). Estes autores relatam que tais híbridos conferiram resistência a $M$. incognita e a $M$. paranaensis, mas que os mesmos têm segregado para essa característica.

O estudo aqui apresentado poderá servir de suporte para as pesquisas, em especial às de melhoramento, que visam à obtenção de plantas resistentes a M. exigua. Assim, com este trabalho objetivou-se avaliar o comportamento reprodutivo de populações de $M$. exigua em genótipos de cafeeiro, visando detectar e identificar a variabilidade existente nessa espécie.

\section{MATERIAL E MÉTODOS}

\section{Origem e caracterização isoenzimática e fisiológica das populações de Meloidogyne exigua}

Foram estudadas quatro populações de M. exigua obtidas de diferentes localidades de modo a abranger, pelo menos, parte da variabilidade existente nesse patógeno, combinando os fenótipos de esterase e as "raças" sugeridas para esta espécie (Esbenshade \&Triantaphyllou, 1985; Carneiro \& Almeida, 2000; Oliveira et al., 2005b). Das 57 populações analisadas por Oliveira et al. (2005b) foram selecionadas duas (população 2 e 3), a população 1 foi caracterizada por Silva et al. (2005) e a população 4 por Santos (1992) e Carneiro \& Almeida (2000).

A confirmação dos fenótipos isoenzimáticos foi realizada pela técnica de eletroforese vertical em sistema descontínuo, conforme Ornstein (1964) e Davis (1964). Cerca de 20 fêmeas de cada população de Meloidogyne, em início de postura e com coloração branco-leitosa, foram retiradas de raízes com galhas e colocadas em micro tubos contendo 10 $\mu \mathrm{L}$ de solução extratora. Para cada população foram utilizadas aproximadamente 240 fềmeas por corrida eletroforética. Após a maceração das fêmeas, os extratos protéicos foram aplicados nas cavidades do gel de poliacrilamida (empilhamento $4 \%$ e separação $8 \%$ ) para subseqüente corrida eletroforética. A etapa de empilhamento foi conduzida a $80 \mathrm{~V}$ por 15 minutos, seguida pela corrida de separação a $200 \mathrm{~V}$ por 35 minutos. Para a reação de esterase foi usada a metodologia descrita em Alfenas (2006).

Para a caracterização das raças de M. exigua, utilizaramse os hospedeiros propostos por Carneiro \& Almeida (2000): tomateiro 'Rutgers', pimentão 'Early California Wonder', cafeeiro 'Catuaí Vermelho IAC 44' e seringueira clone RRIM 600 (Tabela 1).

\section{Avaliação da reação de cafeeiros a populações de Meloidogyne exigua em Coffea spp.}

Durante o período experimental, registraram-se as temperaturas médias mínimas e máximas de 18,7 e $29,7{ }^{\circ} \mathrm{C}$, respectivamente. Estas temperaturas estão entre aquelas que favorecem o desenvolvimento das mudas de cafeeiro (Matiello

TABELA 1 - Caracterização isoenzimática e fisiológica das populações de Meloidogyne exigua

\begin{tabular}{|c|c|c|c|}
\hline Populações & Local de origem & ${ }^{1}$ Fenótipos de esterase & ${ }^{2}$ Raças \\
\hline Pop. 1 & Canaã-MG & E1 $(\mathrm{Rm} 1,60)$ & $\mathrm{R} 1$ \\
\hline Pop. 2 & Muriaé-MG & E1 $(\mathrm{Rm} 1,60)$ & $\mathrm{R} 2$ \\
\hline Pop. 3 & Manhuaçu-MG & E2 $(\mathrm{Rm} 1,60$ e 1,90$)$ & $\mathrm{R} 2$ \\
\hline Pop. 4 & São José do Rio Claro-MT & E1b $(\mathrm{Rm} 1,10$ e 1,60$)$ & $\mathrm{R} 3$ \\
\hline
\end{tabular}

${ }^{1}$ Fenótipos de esterase das populações de Meloidogyne exigua. E1 (Esbenshade \& Triantaphyllou, 1985), E1b (Carneiro \& Almeida, 2000) e E2 (Oliveira et al., 2005a). ${ }^{2}$ Raças de M. exigua conforme Carneiro \& Almeida (2000). Rm = mobilidade relativa. 
\& Almeida, 1997) e ainda favorecem a reprodução de $M$. exigua (Tronconi et al., 1986; Silva et al., 2006).

Empregaram-se genótipos de cafeeiro provenientes do Programa de Melhoramento Genético do Cafeeiro desenvolvido pela EPAMIG/UFV, cultivados no Campo de Adaptação e Seleção de Cafeeiros, em Viçosa, MG (Tabela 4). Estes foram selecionados em razão de terem apresentado resultados contraditórios em estudos prévios com populações de $M$. exigua. São genótipos descendentes do Híbrido de Timor, cruzamento natural entre $C$. arabica e $C$. canephora, e seus derivados: Catimor (Caturra X Híbrido de Timor), Cavimor (Catuaí X Catimor), Sarchimor (Villa Sarchi X Híbrido de Timor) e Icatu (Cruzamento artificial C. arabica X C. canephora). As cultivares Apoatã IAC 2258 e Catuaí Vermelho IAC 44 serviram como padrão de resistência e suscetibilidade, respectivamente.

Sementes de cada um dos genótipos foram semeadas em bandejas contendo areia previamente tratada com brometo de metila $\left(100 \mathrm{~cm}^{3} / \mathrm{m}^{3}\right)$ e colocadas para germinar em câmara de crescimento a temperatura de $30^{\circ} \mathrm{C}$. Quando as plântulas atingiram o estádio de "palito de fósforo" foram transplantadas para vasos de argila com capacidade para 0,5 L, contendo uma mistura de solo e areia 2:1 (v/v), igualmente tratada, e transferidas para a casa de vegetação. A inoculação foi realizada quando as plantas atingiram 3 a 4 pares de folhas definitivas, utilizando-se 5000 ovos por planta. O experimento foi instalado num delineamento inteiramente casualizado, em esquema fatorial (25 genótipos de cafeeiro x 4 populações de $M$. exigua) com 6 repetições.

Decorridos 110 dias da inoculação realizou-se a avaliação das seguintes variáveis: número de galhas (NG) e número de ovos (NO) por sistema radicular. Os ovos foram extraídos segundo o método de Boneti \& Ferraz (1981) e quantificados em câmara de contagem de Peters sob microscópio de luz. Estes dados foram empregados para a determinação do fator de reprodução $(\mathrm{FR}=\mathrm{Pf} / \mathrm{Pi})$, em que $\mathrm{Pf}=$ população final e $\mathrm{Pi}=$ população inicial do nematóide (Oostenbrink, 1966). FR $\leq 1$ confere reação de resistência ao genótipo e FR $>1$ confere reação de suscetibilidade. A massa da matéria fresca das raízes foi avaliada e utilizada para calcular o número de ovos por grama de raiz (NOGR). Os dados foram submetidos à análise de variância e as médias comparadas pelo teste Scott-Knott no programa estatístico SAEG (Euclydes, 1983). Os dados referentes aos genótipos imunes (número de galhas e ovos $=0$ ), os segregantes e os da população oriunda de seringueira, que não infectou o cafeeiro, foram excluídos da análise estatística.

\section{RESULTADOS E DISCUSSÃO}

\section{Avaliação da reação de cafeeiros a populações de Meloidogyne exigua em Coffea spp.}

Os genótipos de Coffea spp. foram divididos em três grupos de acordo com a reação frente às populações de $M$. exigua: 14 genótipos suscetíveis ( $\mathrm{FR} \geq 1, \mathrm{NG}>10$ ) (Tabela 2), 6 segregantes (algumas plantas resistentes $(\mathrm{FR}<1, \mathrm{NG} \leq 10$ ) e outras suscetíveis (Tabela 3 ) e 5 imunes (número de galhas e ovos $=0$ ), tanto pelo critério de Taylor \& Sasser (1978) como pelo proposto por Oostenbrink (1966). Pelo critério adaptado por Moura (1997), que usa a redução do fator de reprodução, esses três grupos de genótipos permaneceram inalterados.

No grupo de genótipos suscetíveis (Tabela 2), não foi

TABELA 2 - Valores médios dos números de galhas (NG), números de ovos (NO) e números ovos por grama de raízes (NOGR) produzidos em genótipos de Coffea spp., classificados como suscetíveis aos 110 dias após a inoculação com 4 populações de Meloidogyne exigua

\begin{tabular}{|c|c|c|c|c|}
\hline Progênies & NG & NO & FR & NOGR \\
\hline \multicolumn{5}{|l|}{ Híbrido de Timor } \\
\hline UFV 1292 & $230 \mathrm{a}$ & $24120 \mathrm{a}$ & 4,82 & $7561 \mathrm{a}$ \\
\hline UFV 1680 & $254 \mathrm{a}$ & $23541 \mathrm{a}$ & 4,71 & $6804 \mathrm{a}$ \\
\hline UFV 1682 & $187 \mathrm{~b}$ & $19465 \mathrm{~b}$ & 3,89 & $6927 \mathrm{a}$ \\
\hline UFV 1804 & $286 \mathrm{a}$ & $26853 \mathrm{a}$ & 5,37 & $6730 \mathrm{a}$ \\
\hline UFV 1824 & $147 \mathrm{~b}$ & $16572 \mathrm{~b}$ & 3,31 & $5363 \mathrm{~b}$ \\
\hline UFV 2389 & $182 \mathrm{~b}$ & $18941 \mathrm{~b}$ & 3,79 & $7174 a$ \\
\hline \multicolumn{5}{|l|}{ Sarchimor } \\
\hline UFV 963 & $327 \mathrm{a}$ & $28767 \mathrm{a}$ & 5,75 & $7511 \mathrm{a}$ \\
\hline \multicolumn{5}{|l|}{ Cavimor } \\
\hline UFV 1076 & $162 \mathrm{~b}$ & $17532 \mathrm{~b}$ & 3,51 & $7155 \mathrm{a}$ \\
\hline \multicolumn{5}{|l|}{ Catimor } \\
\hline UFV 922 & $292 \mathrm{a}$ & $26637 \mathrm{a}$ & 5,33 & $5855 \mathrm{a}$ \\
\hline UFV 951 & $124 \mathrm{~b}$ & $13911 \mathrm{~b}$ & 2,78 & $5434 \mathrm{~b}$ \\
\hline UFV 6869 & $285 \mathrm{a}$ & $27074 \mathrm{a}$ & 5,41 & $6752 \mathrm{a}$ \\
\hline UFV 7577 & $217 \mathrm{~b}$ & $19004 \mathrm{~b}$ & 3,80 & $4885 \mathrm{~b}$ \\
\hline \multicolumn{5}{|l|}{ Icatu } \\
\hline Icatu -39 & $283 \mathrm{a}$ & $27949 \mathrm{a}$ & 5,59 & $6143 a$ \\
\hline \multicolumn{5}{|l|}{ Catuaí } \\
\hline C. Vermelho IAC 44 & $183 \mathrm{~b}$ & $17397 \mathrm{~b}$ & 3,48 & $4993 \mathrm{~b}$ \\
\hline
\end{tabular}

Média de seis repetições. Médias seguidas pela mesma letra na coluna não diferem significativamente, ao nível de $5 \%$ de probabilidade, pelo teste de Scott-Knott. "FR = fator de reprodução, FR $\geq 1=$ suscetíveis (S); FR $<1$ = resistentes (R), segundo Oostenbrink (1966). 
TABELA 3 - Reação de suscetibilidade (S) e resistência (R), valores médios dos números de galhas $(\mathrm{NG})$ e números de ovos $(\mathrm{NO})$ produzidos em genótipos segregantes de Coffea spp., aos 110 dias após a inoculação com 4 populações de Meloidogyne exigua

\begin{tabular}{|c|c|c|c|c|c|c|}
\hline \multirow{2}{*}{ Genótipos } & \multirow{2}{*}{ POP } & \multicolumn{2}{|c|}{ Freqüência de plantas (\%) } & \multirow{2}{*}{ NG } & \multirow{2}{*}{ NO } & \multirow{2}{*}{${ }^{*} \mathbf{F R}$} \\
\hline & & $\mathbf{S}$ & $\mathbf{R}$ & & & \\
\hline \multicolumn{7}{|l|}{ UFV 951} \\
\hline & 1 & 50,00 & 50,00 & 87,00 & 9940,50 & 1,99 \\
\hline & 2 & 66,67 & 33,33 & 107,50 & 12507,00 & 2,50 \\
\hline & 3 & 83,33 & 16,67 & 176,50 & 19285,33 & 3,86 \\
\hline & 4 & 0 & 100,00 & 4,00 & 0 & 0 \\
\hline \multicolumn{7}{|l|}{ UFV 1262} \\
\hline & 1 & 16,67 & 83,33 & 27,80 & 3074,83 & 0,62 \\
\hline & 2 & 16,67 & 83,33 & 18,50 & 2076,17 & 0,42 \\
\hline & 3 & 33,33 & 66,67 & 26,83 & 2992,00 & 0,60 \\
\hline & 4 & 0 & 100,00 & 5,00 & 0 & 0 \\
\hline \multicolumn{7}{|l|}{ UFV1959 } \\
\hline & 1 & 16,67 & 83,33 & 27,16 & 2236,83 & 0,45 \\
\hline & 2 & 0 & 100,00 & 0 & 0 & 0 \\
\hline & 3 & 33,33 & 66,67 & 61,33 & 1724,17 & 0,35 \\
\hline & 4 & 0 & 100,00 & 2,00 & 0 & 0 \\
\hline \multicolumn{7}{|l|}{ H 493 -1 } \\
\hline & 1 & 0 & 100,00 & 4,20 & 0 & 0 \\
\hline & 2 & 16,67 & 83,33 & 39,00 & 3541,67 & 0,71 \\
\hline & 3 & 16,67 & 83,33 & 37,00 & 3102,83 & 0,62 \\
\hline & 4 & 0 & 100,00 & 2,00 & 0 & 0 \\
\hline \multicolumn{7}{|l|}{ H498-14 } \\
\hline & 1 & 33,33 & 66,67 & 36,50 & 3734,33 & 0,75 \\
\hline & 2 & 66,67 & 33,33 & 107,67 & 10858,17 & 2,17 \\
\hline & 3 & 33,33 & 66,67 & 55,83 & 5300,33 & 1,06 \\
\hline & 4 & 0 & 100,00 & 0 & 0 & 0 \\
\hline \multicolumn{7}{|l|}{ H518-2 } \\
\hline & 1 & 16,67 & 83,33 & 39,33 & 2917,50 & 0,58 \\
\hline & 2 & 16,67 & 83,33 & 39,00 & 3091,17 & 0,62 \\
\hline & 3 & 50,00 & 50,00 & 104,17 & 8129,83 & 1,63 \\
\hline & 4 & 0 & 100,00 & 0 & 0 & 0 \\
\hline
\end{tabular}

${ }^{*} \mathrm{FR}$ = fator de reprodução, FR $\geq 1$ = suscetíveis (S); FR $<1$ = resistentes (R), segundo Oostenbrink (1966). Pop 1: população proveniente de Muriaé MG, Pop 2: Manhuaçu MG, Pop 3: Canaã MG, Pop 4: São José do Rio Claro MT.

observada interação significativa entre as populações e os genótipos, mas, evidenciaram-se dois sub-grupos quanto a formação de galhas (NG): no primeiro, os genótipos UFV 922, UFV 963, UFV 1292, UFV 1680, UFV 1804, UFV 6869 e Icatu - 39 apresentaram maior número de galhas, com valores variando de 230 a 327; e no segundo, essa variação foi de 124 a 217. Entretanto, todos os genótipos apresentaram índice de galhas (IG) igual a 5 (> 100 galhas), o que caracteriza a alta suscetibilidade dos mesmos.
Observou-se uma relação direta do NG com o número de ovos (NO) nos genótipos de ambos os grupos. Os valores do fator de reprodução (FR) para o primeiro grupo variou de 4,71 (UFV 1680) a 5,75 (UFV 923), enquanto os do segundo apresentaram FRs entre 2,78 (UFV 951) e 3,89 (UFV 1682). Apesar de ser utilizada como padrão de suscetibilidade, a cultivar Catuaí Vermelho IAC 44 exibiu FR médio de 3,48. De maneira geral, os genótipos que apresentaram os menores números de ovos e, conseqüentemente, menores 
FRs, também exibiram um sistema radicular menos desenvolvido, característica avaliada pela matéria fresca das raízes (MFR) (dados não mostrados). Assim, o número de ovos por grama de raiz (NOGR) poderia expressar melhor a taxa reprodutiva do nematóide (Tabela 2), já que elimina uma fonte de variação, a produção de matéria fresca de raízes, que é característica de cada genótipo. Um exemplo disto, são os genótipos UFV 1682, UFV 2389 e UFV 1076 que passaram a se agrupar com os genótipos que permitiram maior reprodução de $M$. exigua.

Dentre os 25 genótipos, seis segregaram quanto à resistência às populações de $M$. exigua de maneira diferenciada (Tabela 3). As progênies UFV 951, UFV 1262, H 498-14 e H 518-2, segregaram para as três populações de $M$. exigua oriundas de cafeeiro, enquanto as progênies UFV 1959 e H 493-1 segregaram para duas. Das seis plantas de UFV 951 inoculadas com cada população, três foram suscetíveis a população 1 , quatro a população 2 e cinco a população 3. Todas as plantas dessa e das outras progênies foram imunes a população 4 obtida a partir de raízes de seringueira. A progênie UFV 1262 apresentou uma planta suscetível as populações 1 e 2 e duas a população 3 . A progênie UFV 1959 apresentou uma planta suscetível a população 1 e duas a população 3 , já as seis plantas inoculadas com a população 2 foram imunes. A progênie H 493-1 apresentou uma planta suscetível as populações 2 e 3 , e todas as plantas imunes a população 1. A progênie H 498-14 apresentou duas plantas suscetíveis as populações 1 e 3 e quatro a população 2. A progênie H 518-2 apresentou uma planta suscetível as populações 1 e 2 e três a população 3 .

As progênies UFV 981, UFV 1266 e UFV 1848, além dos cultivares Robusta T 3580 c 169 e Apoatã IAC 2258 , não foram infectadas por quaisquer das populações de $M$. exigua avaliadas (ausência de galhas e ovos) e, assim, foram classificadas como imunes (Tabela 4). A população de $M$. exigua oriunda de plantas de seringueira de São José do Rio Claro, MT, não infectou o cafeeiro, não induziu a formação de galhas e não produziu ovos em nenhum dos genótipos avaliados.

O cafeeiro é o hospedeiro tipo de $M$. exigua, contudo apresentou-se como planta não hospedeira da população 4 (seringueira), independente do genótipo estudado. Resultado semelhante foi obtido por Carneiro \& Almeida (2000), embora esses autores tenham inoculado apenas a cultivar Catuaí. Silva et al. (2006) também tentaram, sem sucesso, reproduzir os sintomas em mudas de cafeeiros inoculandoas em quatro estádios de desenvolvimento vegetativo. Esse biótipo poderia ser considerado uma "raça geográfica", que representa categoria intra-específica ou subdivisão de espécies encontradas em diferentes regiões geográficas, presumivelmente adaptadas devido à peculiaridade do ambiente (Sturhan, 1971). Áreas cultivadas com seringueira, como no caso do Mato Grosso, eram tradicionalmente cultivadas com pastagens após o desbravamento do cerrado. Estas áreas não são recomendadas para o plantio do cafeeiro devido às restrições climáticas, principalmente temperaturas elevadas e déficit hídrico (Alfonsi,
2005). Dessa forma, a adaptação fisiológica de $M$. exigua, presente nessa área, poderia ter levado à capacidade de infectar a seringueira quando essa cultura foi implantada.

Outra possibilidade seria considerar esta uma nova espécie, já que o fenótipo para a enzima esterase é diferente dos outros fenótipos encontrados em populações de $M$. exigua coletadas em cafeeiros. E mesmo considerando respostas fisiológicas, essa população não foi capaz de infectar hospedeiros tradicionais dessa espécie, como o tomateiro e o pimentão (Carneiro \& Almeida, 2000). Em análises moleculares utilizando marcadores RAPD, Randig et al. (2002) observaram um alto nível de polimorfismo (67,5\%) entre uma população de seringueira e outra de cafeeiro. Esse grau de polimorfismo parece alto quando se compara as variações intraespecíficas dessa espécie. Carneiro et al. (2004), ao comparar somente populações coletadas de cafeeiro, mas com diferentes habilidades de infectar o tomateiro, observaram apenas 8,6\% de polimorfismo. Entretanto, mais estudos envolvendo outras técnicas moleculares ou marcadores são essenciais de forma a confirmar tais resultados, porque a análise do DNA ribossomal, conduzida por Tenente et al. (2004), mostrou que as populações de M. exigua oriundas do cafeeiro e da seringueira formam um único grupo monofilético.

Considerando que a conceituação de espécie em nematóides é estritamente morfológica, estudos completos acerca da morfologia e morfometria de fêmeas, machos e juvenis de segundo estádio pelo uso de microscopia de luz e eletrônica ainda são requeridos para dirimir as dúvidas referentes ao enquadramento dessa população numa nova espécie. Enquanto tais dados são ainda indisponíveis, considerar-se-á essa população como um biótipo variante dentro da espécie $M$. exigua.

Não foi observada nenhuma interação entre os fenótipos de esterase e a resposta de hospedeiro, como também observado por Oliveira et al. (2005a) ao usar os hospedeiros diferenciadores da Universidade Estadual da Carolina do Norte (USA) e mais algumas plantas citadas como hospedeiras de $M$. exigua.

Alguns autores consideram a presença e o número de galhas como um critério inconsistente para ser utilizado na avaliação de fontes de resistência (Moura, 1997; Asmus et al., 2000). Para sustentar essa posição, argumentam que em culturas resistentes aos nematóides das galhas pode haver formação de galhas sem que haja reprodução do nematóide, e que em algumas plantas suscetíveis pode não ocorrer à formação das mesmas (Moura, 1997). No entanto, a quantidade de galhas induzidas por M. exigua em Coffea spp. expressou uma relação numérica direta com a reprodução do nematóide, como visto pelo NO e FR. Diante disso, o número de galhas induzidas por M. exigua pode ser considerado um real indicador de diferenças na reprodução do nematóide entre genótipos de cafeeiros. Essa consistência na relação galhas (sintomas) e NO (reprodução) já têm sido observados também por outros autores (Gonçalves \& Pereira, 1998; Bertrand et al., 2001; Silva et al., 2003; Silva et al., 2006). A vantagem que se pode tirar dessa informação é que em fases iniciais dos programas de melhoramento do cafeeiro 
TABELA 4 - Reação de 28 genótipos de Coffea spp. frente a 8 populações de Meloidogyne exigua (P1 a P4 avaliadas no presente estudo e as demais estudadas por outros autores)

\begin{tabular}{|c|c|c|c|c|c|c|c|c|}
\hline \multirow[b]{2}{*}{ Genótipos de Coffea spp. } & \multicolumn{8}{|c|}{ Populações de Meloidogyne exigua } \\
\hline & P1 & $\overline{\mathbf{P 2}}$ & $\overline{\mathbf{P 3}}$ & P4 & P5 & P6 & P7 & P8 \\
\hline \multicolumn{9}{|l|}{ Híbrido Timor } \\
\hline UFV 963 & $\mathrm{~S}$ & $\mathrm{~S}$ & $\mathrm{~S}$ & I & $\mathrm{S}$ & - & - & - \\
\hline UFV 981 & I & I & I & I & I & - & - & - \\
\hline UFV 1262 & $\mathrm{R}(\mathrm{Se})$ & $\mathrm{R}(\mathrm{Se})$ & $\mathrm{R}(\mathrm{Se})$ & I & $\mathrm{R}$ & $\mathrm{R}^{*}$ & $\mathrm{R}(\mathrm{Se})^{*}$ & $\mathrm{R}$ \\
\hline UFV 1266 & I & I & I & I & I & I & I & I \\
\hline UFV 1292 & $\mathrm{~S}$ & $\mathrm{~S}$ & $\mathrm{~S}$ & I & $\mathrm{S}$ & $\mathrm{S}^{*}$ & $\mathrm{~S}^{*}$ & - \\
\hline UFV 1680 & $\mathrm{~S}$ & $\mathrm{~S}$ & $\mathrm{~S}$ & I & $\mathrm{R}$ & $\mathrm{R}$ & $\mathrm{S}$ & $\mathrm{R}$ \\
\hline UFV 1682 & $\mathrm{~S}$ & $\mathrm{~S}$ & S & I & $\mathrm{S}$ & $\mathrm{S}^{*}$ & $\mathrm{~S}^{*}$ & - \\
\hline UFV 1804 & $\mathrm{~S}$ & $\mathrm{~S}$ & $\mathrm{~S}$ & I & $\mathrm{R}$ & $\mathrm{S}$ & $\mathrm{S}$ & S \\
\hline UFV 1824 & $\mathrm{~S}$ & $\mathrm{~S}$ & $\mathrm{~S}$ & I & $\mathrm{S}$ & $\mathrm{S}^{*}$ & $\mathrm{~S}^{*}$ & - \\
\hline UFV 1825 & - & - & - & - & $\mathrm{R}$ & $\mathrm{S}$ & $\mathrm{S}$ & S \\
\hline UFV 1848 & I & I & I & I & I & I & I & I \\
\hline UFV 1959 & $\mathrm{R}(\mathrm{Se})$ & I & $\mathrm{R}(\mathrm{Se})$ & I & $\mathrm{R}$ & $\mathrm{R}$ & $\mathrm{R}$ & $\mathrm{R}$ \\
\hline UFV 2389 & $\begin{array}{l}1 \\
S\end{array}$ & $\mathrm{~S}$ & $\mathrm{~S}$ & I & - & - & - & - \\
\hline \multicolumn{9}{|l|}{ Cavimor } \\
\hline UFV 1076 & $\mathrm{~S}$ & $\mathrm{~S}$ & $\mathrm{~S}$ & I & - & - & - & - \\
\hline \multicolumn{9}{|l|}{ Catimor } \\
\hline UFV 922 & $\mathrm{~S}$ & $\mathrm{~S}$ & $\mathrm{~S}$ & I & - & - & - & - \\
\hline UFV 951 & $\mathrm{~S}(\mathrm{Se})$ & $\mathrm{S}(\mathrm{Se})$ & $\mathrm{S}(\mathrm{Se})$ & I & - & - & - & - \\
\hline UFV 6572 & - & - & - & - & $\mathrm{R}$ & $\mathrm{S}$ & $\mathrm{S}^{*}$ & $\mathrm{~S}$ \\
\hline UFV 6619 & - & - & - & - & $\mathrm{R}$ & $\mathrm{S}$ & $\mathrm{S}^{*}$ & S \\
\hline UFV 6869 & $\mathrm{~S}$ & $\mathrm{~S}$ & $\mathrm{~S}$ & I & $\mathrm{S}$ & $\mathrm{S}$ & - & - \\
\hline UFV 7577 & $\mathrm{~S}$ & $\mathrm{~S}$ & $\mathrm{~S}$ & I & $\mathrm{R}$ & - & - & - \\
\hline UFV 7595 & I & I & I & I & $\mathrm{R}$ & $\mathrm{R}$ & $\mathrm{R}$ & $\mathrm{R}$ \\
\hline \multicolumn{9}{|l|}{ Icatu } \\
\hline Icatu - 39 & $\mathrm{~S}$ & $\mathrm{~S}$ & $\mathrm{~S}$ & I & $\mathrm{S}$ & - & - & - \\
\hline \multicolumn{9}{|l|}{ Híbridos } \\
\hline H $493-1$ & I & $\mathrm{R}(\mathrm{Se})$ & $\mathrm{R}(\mathrm{Se})$ & I & - & $\mathrm{S}$ & $\mathrm{S}$ & S \\
\hline H $498-14$ & $\mathrm{R}(\mathrm{Se})$ & $\mathrm{S}(\mathrm{Se})$ & $\mathrm{S}(\mathrm{Se})$ & I & $\mathrm{R}(\mathrm{Se})$ & - & $\mathrm{S}$ & $\mathrm{S}$ \\
\hline Н $518-2$ & $\mathrm{R}(\mathrm{Se})$ & $\mathrm{R}(\mathrm{Se})$ & $\mathrm{S}(\mathrm{Se})$ & I & - & $\mathrm{R}$ & $\mathrm{S}$ & $\mathrm{R}$ \\
\hline \multicolumn{9}{|l|}{ C. arabica } \\
\hline Catuaí V. IAC 44 & $\mathrm{~S}$ & $\mathrm{~S}$ & $\mathrm{~S}$ & I & $\mathrm{S}$ & $\mathrm{S}$ & $\mathrm{S}$ & S \\
\hline \multicolumn{9}{|l|}{ C. canephora } \\
\hline Robusta T 3580 & I & I & I & I & - & - & - & - \\
\hline Apoatã IAC 2258 & I & I & I & I & I & I & I & I \\
\hline
\end{tabular}

Reação: $\mathrm{S}$ = suscetível, $\mathrm{Se}$ = segregante, $\mathrm{R}$ = resistente, I = imune, - = não avaliada. (Oostenbrink, 1966; Taylor \& Sasser, 1978; Moura, 1997); P1: população proveniente de Muriaé/MG, P2: Manhuaçu/MG, P3: Canaã/MG, P4: São José do Rio Claro/MT. P5: São Sebastião do Paraíso/MG, Gonçalves \& Pereira, 1998). P6: Mirai/MG (Ribeiro et al. 2005). P7: Fervedouro e P8 : Caratinga/ MG (A.A. Pereira. Dados não publicados). * Genótipos avaliados por Silva et al. (2003) usando as populações 5 e 6.

visando à resistência a $M$. exigua, é possível avaliar apenas o número de galhas como expressão da suscetibilidade das progênies. Considerando que nessas fases o número de progênies avaliadas é muito alto, a utilização do número de galhas, como critério para a avaliação da resistência resultaria numa grande economia de tempo e sem perder em confiabilidade.

As progênies UFV 981, UFV 1266 e UFV 1848, além dos cultivares Robusta T 3580 c 169 e Apoatã IAC 2258, apresentaram reação de imunidade a todas as populações de $M$. exigua estudadas. Aqui foi seguida a conceituação estabelecida por Moura (1997) que define imunidade à meloidoginose como ausência de reprodução do nematóide na interação Meloidogyne - planta hospedeira. Outra informação a ser ressaltada é que esses genótipos também apresentam resistência ao fungo
Hemileia vastatrix, agente causal da ferrugem do cafeeiro (Pereira, A.A. comunicação pessoal). Essa característica eleva-os a uma categoria superior de doadores de genes num programa de melhoramento. Diante do exposto, tais genótipos, que fazem parte do Programa de Melhoramento Genético do Cafeeiro desenvolvido pela EPAMIG/UFV, Viçosa MG, mostram-se promissores como fontes de resistência conjunta a dois importantes patógenos do cafeeiro no Brasil.

Alguns genótipos segregaram quanto à reação de resistência/suscetibilidade frente às populações oriundas de cafeeiro. Noir et al. (2003), ao analisar a herança da resistência de cafeeiros a $M$. exigua, observaram segregação próxima de 3:1, herança mendeliana simples, controlada por um gene maior dominante para a resistência, designado no 
Respostas de genótipos de Coffea spp. a diferentes populações...

loco Mex - 1. Este fato deve ser considerado nos programas de melhoramento por ocasião da classificação das progênies. Quando as plantas são avaliadas e se depara com uma ou mais repetições exibindo reação suscetível, e as demais resistentes, é comum encontrar a média dos FRs menor que 1, o que levaria a classificar o material erroneamente como resistente. Tal fato ocorreu com algumas progênies como a H 493-1 cujos FRs médios foram 0,71 e 0,62 para as populações de $M$. exigua 2 e 3, respectivamente. Esses resultados permitem apenas dizer que tais progênies se encontram em fase de segregação quanto à resistência $\mathrm{a} M$. exigua, ou seja, exibindo plantas resistentes $\mathrm{e}$ outras suscetíveis.

Resultados obtidos por Gonçalves \& Pereira (1998), Silva et al. (2003) e Ribeiro et al. (2005) demonstraram que algumas progênies derivadas do Híbrido de Timor, como a UFV 1262 e UFV 1680, responderam de forma diferenciada às populações de $M$. exigua originárias dos municípios de São Sebastião do Paraíso, Fervedouro e Miraí, MG. Embora cada grupo de pesquisadores tenha trabalhado apenas com uma população do nematóide, tais informações reforçam os resultados obtidos no presente trabalho, por mostrar a existência de um comportamento diferenciado entre populações de $M$. exigua em Coffea spp.

Lashermes et al. (2000), em análise molecular da introgressão de genes de C. canephora em C. arabica, observaram que, apesar de derivado de um único híbrido interespecífico, os genótipos derivados do Híbrido de Timor mostraram grande diversidade genética. Foi detectado nesses genótipos pelo menos o dobro da diversidade genética apresentada nos cultivares de C. arabica. Essa diversidade deve ser considerada, juntamente com a variabilidade do patógeno, em programas de melhoramento de cafeeiro visando selecionar fontes de resistência a $M$. exigua. Os resultados obtidos no presente estudo, demonstraram que o uso de diferentes populações desse patógeno, que englobem a variabilidade existente no mesmo, é fundamental no desenvolvimento de cultivares resistentes de cafeeiro num programa de melhoramento.

\section{AGRADECIMENTOS}

O primeiro autor agradece à concessão da bolsa de mestrado pela CAPES; os autores agradecem a Dra. Regina M.D.G. Carneiro (EMBRAPA/CENARGEN) pelo envio da população 4 do nematóide, indispensável para a realização deste trabalho.

\section{REFERÊNCIAS BIBLIOGRÁFICAS}

ALFONSI, R.R. Zoneamento Climático da Cultura do Café (Texto). Disponível em: <http://www.cpa.unicamp.br htm> Acesso em 20 de fevereiro de 2005.

ALFENAS, A.C. Eletroforese e marcadores bioquímicos em plantas e microrganismos. 2. ed. Viçosa MG. Editora UFV. 2006.
ASMUS, G.L., FERRAZ, L.C.C.B. \& APPEZZATO-DAGLÓRIA, B. Alterações anatômicas em raízes de milho (Zea mays L.) parasitadas por Meloidogyne javanica. Nematropica 30:33-39. 2000.

BARBOSA, D.H.S.G., VIEIRA, H.D., SOUZA, R.M., VIANA, A.P. \& SILVA, C.P. Field estimates of coffee yield losses and damage threshold by Meloidogyne exigua. Nematologia Brasileira 28:49-54. 2004.

BERTRAND, B.T., ANTHONY, F. \& LASHERMES, P. Breeding for resistance to Meloidogyne exigua in Coffea arabica by introgression of resistance genes of Coffea canephora. Plant Pathology 50:637-643. 2001.

BONETI, J.I.S. \& FERRAZ, S. Modificação do método de Hussey \& Barker para extração de ovos de Meloidogyne exigua de raízes de cafeeiro. Fitopatologia Brasileira 6:553. 1981. (Resumo)

CAMPOS, V.P. \& VILLAIN, L. Nematode parasites of coffee and cocoa. In: Luc, M., Sikora, R. A. \& Bridge, J. (Eds.) Plant parasitic nematodes in subtropical and tropical agriculture. Wallingford UK. CAB Internacional. 2005. pp. 529-579.

CARNEIRO, R.M.D.G. \& ALMEIDA, M.R.A. Caracterização isoenzimática e variabilidade intraespecífica dos nematóides de galhas do cafeeiro no Brasil. In: Simpósio de Pesquisa dos Cafés do Brasil. Anais, Poços de Caldas, MG. 2000. pp. 280-282.

CARNEIRO, R.M.D.G., TIGANO, M.S., RANDIG, O., ALMEIDA, M.R.A. \& SARAH J.L. Identification and genetic diversity of Meloidogyne spp. (Tylenchida: Meloidogynidae) on coffee from Brazil, Central America and Hawaii. Nematology 6:287-298. 2004.

CONAB. 2006. Companhia Nacional de Abastecimento-Secretaria da Produção e Comercialização/CONAB. Safra brasileira de café estimada 2005/2006. Disponível em: < http://www.agricultura.gov. br/spc.htm> Acesso 20 abril de 2006.

CROS, J. Implications phylogénetiques des variations de 1 ADN chloroplastic chez les caféiers (genres Coffea L. et Psilanthus Hook. F.) PhD Thesis. Montpellier. Universite Montpellier II. 1994.

DAVIS, B.J. Disc electrophoreses. II. Method end Application to human serum proteins. Annals of the New York Academy of Sciences 121:404-427. 1964

EUCLYDES, R.F. Manual de utilização do programa SAEG (Sistema para Análises Estatística e Genética). Viçosa MG. Universidade Federal de Viçosa. 1983.

ESBENSHADE, P.R. \& TRIANTAPHYLLOU, A.C. Electrophoretic methods for the study of root-knot nematode enzymes. In: Barker, K.R., Carter, C.C. \& Sasser, J.N. (Eds.) An advanced treatise on Meloidogyne. North Carolina State University Graphics. 1985. pp. 115-123.

GONÇALVES, W. \& PEREIRA, A.A. Resistência de cafeeiro a nematóides IV. Reação do cafeeiro derivados do Híbrido de Timor a Meloidogyne exigua. Nematologia Brasileira 22:39-49. 1998.

GONÇALVES, W. \& SILVAROLLA, M.B. Nematóides parasitos do cafeeiro. In: Zambolim, L. (Ed.) Tecnologias de produção de café com qualidade. Viçosa MG. Editora UFV. 2001. pp. 199-267.

LASHERMES, P., ANDRZEWSKI, S., BERTRAND, B., COMBES, M.C., DUSSERT, G., TROUSLOT, P. \& ANTHONY, F. Molecular analysis of introgressive breeding in coffee (Coffea arabica L.). Theoretical and Applied Genetics 100:139-146. 2000. 
MATIELLO, J.B \& ALMEIDA, S.R. Variedades de café, como escolher, como plantar. Rio de Janeiro, RJ. MAA/SDR/PROCAFÉ. 1997.

MOURA, R.M. O gênero Meloidogyne e a meloidoginose parte II. Revisão Anual de Patologia de Plantas 5:281-315. 1997.

NOIR, S., ANTHONY, F., BERTRAND, B., COMBES, M.C. \& LASHERMES, P. Identification of a major gene (Mex-1) from Coffea canephora conferring resistance to Meloidogyne exigua in Coffea arabica. Plant Pathology 52:97-103. 2003.

OLIVEIRA, D.S., OLIVEIRA, R.D.L. \& SILVA, R.V. Caracterização fisiológica de populações de Meloidogyne exigua associados a cafeeiros na Zona da Mata de Minas Gerais. Nematologia Brasileira 29:279-283. 2005a.

OLIVEIRA, D.S., OLIVEIRA, R.D.L., FREITAS, L.G. \& R.V. SILVA. Variability of Meloidogyne exigua on Coffee in the Zona da Mata of Minas Gerais State, Brazil. Journal of Nematology 37:323327. 2005b.

OOSTENBRINK, M. 1966. Major characteristics of the relation between nematodes and plants. Mendelingen Landbouwhogeschool Wageningen 66:1- 46.

ORNSTEIN, L. Disc electrophoreses. I. Background and Theory. Annals of the New York Academy of Sciences 121:321-349. 1964.

RANDIG, O., BONGIOVANNI, M., CARNEIRO, R.M.D.G. \& CASTAGNONE SERENO, P. Genetic diversity of root-knot nematodes from Brazil and development of SCAR markers specific for the coffee-damaging species. Genome 45:862-870. 2002.

RIBEIRO, R.C.F., PEREIRA, A.A., OLIVEIRA, C.H. \& LIMA, R.D. Resistência de progênies de híbridos interespecíficos de Coffea arabica e Coffea canephora a Meloidogyne exigua. Nematologia Brasileira 29:11-16. 2005.

ROBERTS, P.A., MATTHEWS, W.C. \& VEREMIS, J.C. Genetic mechanisms of host plant resistance to nematodes. In: Barker, K.R., Pederson, G.A. \& Windham, G.L. (Eds.) Plant and nematode interactions. Madison WI. American Society of Agronomy Inc. 1998. pp. 209-238.

SANTOS, J.M., MATTOS, C., BARRÉ, L. \& FERRAZ, S. Meloidogyne exigua, sério patógeno da seringueira nas plantações. In: Michelin, em Rondonópolis, MT. In: Resumos, Congresso Brasileiro de Nematologia, Lavras MG. p.75. 1992. (Resumo)

SILVA, R.V., OLIVEIRA, R.D.L., PEREIRA, A.A. \& PINTO, F.S. Variabilidade de Meloidogyne exigua em genótipos de cafeeiro. Fitopatologia Brasileira 28(Supl.):293. 2003. (Resumo)

SILVA, R.V. Produção de inóculo e diferenciação de raças de Meloidogyne exigua em Coffea spp. Dissertação de Mestrado. Viçosa MG. Universidade Federal de Viçosa. 2005.

SILVA, R.V., OLIVEIRA, R.D.L., PEREIRA, A.A. \& SÊNI, D.J. Otimização da produção de inóculo de Meloidogyne exigua em mudas de cafeeiro. Nematologia Brasileira 30:229-238. 2006.

STURHAN, D. Biological races. In: Zuckerman, B.M., Mai, W.F. \& Rohde, R.A. (Eds.) Plant Parasitic Nematodes. New York NY. Academic Press. 1971. pp. 51-71.

TAYLOR, A.L. \& SASSER, J.N. Biology, identification and control of root-knot nematodes (Meloidogyne spp.). Coop. Publ. Dep. Plant. Pathol. Raleigh NC. North Carolina State University Graphics. 1978.

TENENTE, G.C.M.V., DE LEY, P., TANDINGRAN DE LEY, I., KARSSEN, G. \& VANFLETEREN, J.R. Sequence analysis of the D2/D3 region of the large subunit rDNA from different Meloidogyne isolates. Nematropica 34:1-12. 2004.

TRONCONI, N.M., FERRAZ, S., SANTOS, J.M. \& REGAZZI, A.J. Influência da temperatura na patogenicidade e reprodução de Meloidogyne exigua em mudas de cafeeiro. Nematologia Brasileira 10:69-83. 1986.

Recebido 14 Novembro 2006 - Aceito 15 Junho 2007 - FB 6115 